OPEN ACCESS

Edited by:

Zhenbo Xu,

University of Maryland, Baltimore,

United States

Reviewed by:

Giacomo Zara,

University of Sassari, Italy

Agustin Aranda,

Instituto de Biología Integrativa de Sistemas (UV+CSIC), Spain

*Correspondence: Eirini Vitzilaiou eirini@food.ku.dk

Specialty section:

This article was submitted to

Food Microbiology,

a section of the journal

Frontiers in Microbiology

Received: 20 December 2019

Accepted: 06 April 2020

Published: 05 May 2020

Citation:

Vitzilaiou E, Aunsbjerg SD,

Mahyudin NA and Knøchel S (2020)

Stress Tolerance of Yeasts

Dominating Reverse Osmosis

Membranes for Whey Water

Treatment. Front. Microbiol. 11:816.

doi: 10.3389/fmicb.2020.00816

\section{Stress Tolerance of Yeasts Dominating Reverse Osmosis Membranes for Whey Water Treatment}

\author{
Eirini Vitzilaiou ${ }^{1 *}$, Stina D. Aunsbjerg ${ }^{1}$, N. A. Mahyudin² and Susanne Knøchel1 \\ 1 Laboratory of Microbiology and Fermentation, Department of Food Science, University of Copenhagen, Copenhagen, \\ Denmark, ${ }^{2}$ Department of Food Service and Management, Faculty of Food Science and Technology, Universiti Putra \\ Malaysia, Serdang, Malaysia
}

Filamentous yeast species belonging to the closely related Saprochaete clavata and Magnusiomyces spicifer were recently found to dominate biofilm communities on the retentate and permeate surface of Reverse Osmosis $(\mathrm{RO})$ membranes used in a whey water treatment system after CIP (Cleaning-In-Place). Microscopy revealed that the two filamentous yeast species can cover extensive areas due to their large cell size and long hyphae formation. Representative strains from these species were here further characterized and displayed similar physiological and biochemical characteristics. Both strains tested were able to grow in twice $\mathrm{RO}$-filtrated permeate water and metabolize the urea present. Little is known about the survival characteristics of these strains. Here, their tolerance toward heat $\left(60,70\right.$, and $\left.80^{\circ} \mathrm{C}\right)$ and Ultraviolet light (UV-C) treatment at $255 \mathrm{~nm}$ using UV-LED was assessed as well as their ability to form biofilm and withstand cleaning associated stress. According to the heat tolerance experiments, the $D_{60}{ }^{\circ} \mathrm{C}$ of $S$. clavata and $M$. spicifer is $16.37 \mathrm{~min}$ and $7.24 \mathrm{~min}$, respectively, while a reduction of 3.5 to $>4.5$ $\log (\mathrm{CFU} / \mathrm{mL})$ was ensured within $5 \mathrm{~min}$ at $70^{\circ} \mathrm{C}$. UV-C light at a dose level $10 \mathrm{~mJ} / \mathrm{cm}^{2}$ had little effect, while doses of $40 \mathrm{~mJ} / \mathrm{cm}^{2}$ and upward ensured a $\geq 4 \log$ reduction in a static laboratory scale set-up. The biofilm forming potential of one filamentous yeast and one budding yeast, Sporopachydermia lactativora, both isolated from the same biofilm, was compared in assays employing flat-bottomed polystyrene microwells and peg lids, respectively. In these systems, employing both nutrient rich as well as nutrient poor media, only the filamentous yeast was able to create biofilm. However, on RO membrane coupons in static systems, both the budding yeast and a filamentous yeast were capable of forming single strain biofilms and when these coupons were exposed to different simulations of CIP treatments both the filamentous and budding yeast survived these. The dominance of these yeasts in some filter systems tested, their capacity to adhere and their tolerance toward relevant stresses as demonstrated here, suggest that these slow growing yeasts are well suited to initiate microbial biofouling on surfaces in low nutrient environments.

Keywords: filamentous yeast, biofilm, CIP, reverse osmosis, heat tolerance, UV tolerance 


\section{INTRODUCTION}

Filamentous yeasts are emerging as highly potent biofilmforming microorganisms in water distribution systems (Doggett, 2000; Babič et al., 2017), residential dishwashers (Zalar et al., 2011; Döğen et al., 2013; Gümral et al., 2016; Zupančič et al., 2016) and in food industrial equipment (Tang et al., 2009; Tarifa et al., 2013; Stoica et al., 2018; Vitzilaiou et al., 2019). These findings indicate that filamentous yeasts can disperse efficiently, attach strongly to different surfaces and create robust hyphal networks capable of surviving several stresses. According to the study of Paramonova et al. (2009), an increase in hyphae content will strengthen the fungal biofilm and the resistance to such stresses as compression, vortexing and sonication. It has also been shown that filamentous yeasts can develop synergistic relationships with bacteria, leading to vigorous polymicrobial biofilm structures (Shirtliff et al., 2009; De Brucker et al., 2015; Zupančič et al., 2018).

Spiral wound RO membranes are widely used in the food industry and the recovered watery permeate may be used for different purposes. The membranes offer high filtration efficiency, but they are susceptible to biofouling causing flux reduction and shortening of membrane life (Herzberg and Elimelech, 2007; Tang et al., 2009; Anand et al., 2012, 2013; Stoica et al., 2018). Biofouling may also become an issue for final product quality, if microbial cells from the biofilms are capable of proliferating further down the processing line or in the water permeate during storage, since the water may be used for cleaning or for direct/indirect product contact processes (Casani and Knøchel, 2002; Casani et al., 2005).

Over the last decades, there has been an increasing interest in spiral wound RO membrane biofouling in the food processing industry (Tang et al., 2009; Hassan et al., 2010; Anand et al., 2012, 2013; Sánchez, 2018; Stoica et al., 2018; Vitzilaiou et al., 2019). Up to now, research has been mainly focused on bacterial contamination. In 2009, however, a filamentous yeast isolate was observed among the bacterial isolates on RO membranes from a dairy industry in New Zealand. It was isolated from the retentate side of $\mathrm{RO}$ elements used for processing casein water permeate and identified as the filamentous yeast Blastoschizomyces capitatus (Tang et al., 2009), later renamed Magnusiomyces capitatus (Sybren De Hoog and Smith, 2011a).

We have recently documented that filamentous yeasts belonging to the closely related species Saprochaete clavata and Magnusiomyces spicifer may dominate biofilms found after CIP treatment on both sides of RO membranes filtering whey water (Stoica et al., 2018; Vitzilaiou et al., 2019). Although these biofilms may have a great impact on RO filtration efficiency, little is known about these isolates and their response to the stress encountered. Here, our aim is to characterize two representative strains of these filamentous yeasts (S. clavata and M. spicifer) isolated from RO elements (Stoica et al., 2018; Vitzilaiou et al., 2019) with focus on properties of importance for survival and growth in the processing environment. Morphological and physiological-biochemical tests were conducted and the heat and UV-C (255 nm) light tolerance of the filamentous yeasts was investigated. The ability of one of the filamentous yeasts to create biofilms on polystyrene flat-bottomed microwells and on peg lids, respectively, was assessed and compared to that of a budding yeast strain, Sporopachydermia lactativora, found on the same biofilm structures. The tolerance of biofilms on RO membrane coupons was tested toward different industrial CIP-mimicking treatments in lab-scale experiments to broaden our knowledge about these RO membrane biofouling agents and facilitate future development of targeted cleaning operations.

\section{MATERIALS AND METHODS}

\section{Yeast Strains' Isolation}

The filamentous yeast strains belonging to $S$. clavata and $M$. spicifer and the budding yeast strain belonging to $S$. lactativora, investigated here, are representative strains from the total number of yeast species previously isolated from a RO membrane filtration line for water reuse in a dairy industry (Stoica et al., 2018; Vitzilaiou et al., 2019). S. clavata and $M$. spicifer found to be the dominant yeast species and $S$. lactativora the most commonly found budding yeast in the detected biofilm structures. In the set up investigated, the whey was up-concentrated through Ultrafiltration (UF) and the permeate solution further subjected to two consecutive RO filtrations and two UV-C (Ultraviolet) light steps before reuse. Sampling, isolation and sequencing procedures are described in Stoica et al. (2018) and Vitzilaiou et al. (2019).

\section{Macroscopic and Microscopic Characterization}

Phase-contrast microscopy using the upright microscope Olympus BX43 (Olympus Scientific Solutions Americas Corp.) was used to observe the yeast cells grown in YPG broth $(20 \mathrm{~g} / \mathrm{L}$ Glucose, $20 \mathrm{~g} / \mathrm{L}$ Peptone, $10 \mathrm{~g} / \mathrm{L}$ Yeast Extract, pH $5.6 \pm 0.2$ ) at $25^{\circ} \mathrm{C}$ with shaking at $225 \mathrm{rpm}$ (orbital shaker: IKA KS 130 control) and Malt Extract Agar (MEA) at $25^{\circ} \mathrm{C}$ (CM0059/Oxoid).

\section{Strains Used for Physiological-Biochemical Tests}

An isolate from each of the two dominant filamentous yeast species was selected for physiological-biochemical tests. These isolates will be referred to as SC, for Saprochaete clavata and MS, for Magnusiomyces spicifer, throughout the rest of the paper. Growth at different temperatures $(5,25,30,35,37,40$, and $45^{\circ} \mathrm{C}$ ) without shaking was assessed in $10 \mathrm{~mL}$ YPG broth tubes, inoculated with an individual colony (MEA agar plates $/ 25^{\circ} \mathrm{C}$ ) with triplicates for each isolate and temperature. Fermentation of carbohydrates (D-glucose, D-galactose, sucrose, maltose, lactose, raffinose, and trehalose) and assimilation of carbon compounds (D-glucose, D-galactose, sucrose, maltose, lactose, raffinose, trehalose, D-xylose, L-sorbose, cellobiose, salicin, DLlactate, succinate, citrate) and nitrate were tested in tubes, in triplicates, incubated at $25^{\circ} \mathrm{C}$ without shaking, according to the experimental procedure of Kurtzman et al. (2011). Growth at different temperatures and results of fermentation and assimilation experiments were assessed after 1,2, 3, and 
4 weeks of incubation, respectively, using the Wickerham card. Urease activity was tested using Christensen's urea broth (Kurtzman et al., 2011).

\section{Growth in Twice RO-Filtrated Water}

The ability of SC and $M S$ to grow in the twice RO-filtrated permeate water was assessed. One individual colony from SC and $M S$, respectively, was inoculated in tubes containing $10 \mathrm{~mL}$ of twice RO-filtrated permeate water from the same line (stored in the fridge $\left./ 4^{\circ} \mathrm{C}\right)$. After inoculation, the tubes were incubated for 3 days at $25^{\circ} \mathrm{C}$ with shaking at $225 \mathrm{rpm}$. These tubes and the noninoculated control sample (twice RO-filtrated permeate water) were analyzed to determine the urea and ammonia concentration using an enzyme assay as described by the manufacturer (Megazymes, United Kingdom).

\section{Heat Tolerance Assay}

Planktonic cell suspensions of $S C$ and $M S$ in Saline Peptone Solution (SPS) [1 g/L Bacto Peptone (Difco 211677), $8.5 \mathrm{~g} / \mathrm{L}$ sodium chloride, pH 7.2 \pm 0.2 ] were exposed to 60,70 , and $80^{\circ} \mathrm{C}$ for $5,10,15$, and $20 \mathrm{~min}$, and the CFU/mL determined on MYPG agar $(10 \mathrm{~g} / \mathrm{L}$ glucose, $5 \mathrm{~g} / \mathrm{L}$ peptone, $3 \mathrm{~g} / \mathrm{L}$ yeast extract, $3 \mathrm{~g} / \mathrm{L}$ malt extract, $20 \mathrm{~g} / \mathrm{L}$ agar, $\mathrm{pH} 5.6 \pm 0.1$ ) in order to assess the heat tolerance. For the inocula, the two filamentous yeast isolates ( $S C$ and $M S$ ) were incubated separately on MYPG agar plates at $25^{\circ} \mathrm{C}$ for 3 days. For each of them, material from an individual colony was inoculated into $20 \mathrm{~mL}$ YPG broth tubes and incubated with shaking at $25^{\circ} \mathrm{C}$ for 2 days. Cells were harvested from the liquid cultures by centrifugation $\left(3,000 \mathrm{~g} / 5 \mathrm{~min} / 4^{\circ} \mathrm{C}\right)$. The supernatant was removed, cold $\left(4^{\circ} \mathrm{C}\right)$ SPS added, and the pellet washed by vortexing, followed by centrifugation. This procedure was repeated twice, and the pellet was re-suspended in $20 \mathrm{~mL}$ SPS and vortexed. The Neubauer counting chamber was used to create a $10^{7}$ cells $/ \mathrm{mL}$ inoculum in SPS. For each temperature-time interval, $1.5 \mathrm{~mL}$ sterile eppendorf tubes with $990 \mu \mathrm{L}$ SPS were inserted in the pre-heated heating blocks and the temperature monitored in a control tube. When the solution reached the desired temperature, $10 \mu \mathrm{L}$ from the initial inoculum was added to the eppendorf tubes for a final concentration of $10^{5}$ cells $/ \mathrm{mL}$. Triplicates were made for each isolate and temperature-time interval. After each designated temperature-time interval, tubes were placed in ice and serial dilutions made in SPS followed by spread plating on MYPG agar plates. Initial inocula were also validated on MYPG agar. Colonies were counted after 10 days of incubation at $25^{\circ} \mathrm{C}$, to allow for growth of injured cells. $D$-values for $60^{\circ} \mathrm{C}$ for $S C$ and $M S$ were calculated using linear regression analysis (Murphy et al., 2000, 2002; McCormick et al., 2003).

\section{UV-C Light Treatment}

UV-C light treatment at $254 \mathrm{~nm}$ of $40 \mathrm{~mJ} / \mathrm{cm}^{2}$ is commonly applied to RO permeate water in the finishing steps before storage and reuse. The tolerance of the two filamentous yeast isolates to UV-C light treatment was investigated, using PearlLab Beam Device from AquiSense Technologies (Kentucky, United States), a compact Collimated Beam Device employing UV-LEDs and emitting UV-C irradiation at $255 \mathrm{~nm}$, following the Bolton and Linden (2003) and Bolton et al. (2015) protocols. The inoculum was prepared as described in Section "Heat Tolerance Assay" and the inoculum concentration set at $10^{6}$ cells $/ \mathrm{mL}$. The (\%) UV transmittance of the SPS microbial suspension at $255 \mathrm{~nm}$ (UV-Vis 1800 spectrophotometer, Shimadzu) was measured to calculate the water factor. The center point irradiance $\left[E_{o},\left(\mathrm{~mW} / \mathrm{cm}^{2}\right)\right]$ of the UV-C LED device was determined (radiometer ILT2400, International Light Technologies) and used together with the water factor, petri factor, divergence factor, and sensor factor to calculate the average germicidal fluence rate $\left(E^{\prime}\right.$ avg $)$. To obtain the exposure time ( $\mathrm{sec}$ ) for a desired UV dose, this dose $\left(\mathrm{mJ} / \mathrm{cm}^{2}\right)$ was divided by the average fluence rate $\left(\mathrm{mW} / \mathrm{cm}^{2}\right)$. The selected UV doses were 10, 20, 40,60, and $100 \mathrm{~mJ} / \mathrm{cm}^{2}$. The exposure time (sec) needed to achieve the desired UV-doses was calculated according to the protocol. Four individual trials were conducted with two replicates within each trial. For each UV dose, $20 \mathrm{~mL}$ inoculum $\left(4^{\circ} \mathrm{C}\right)$ were transferred to a $50 \mathrm{~mm}$ sterile petri dish and exposed to UV-C light for specific time (sec) to achieve the desired dose. The cell suspensions were continuously stirred during the experiments. UV doses were applied in a random order. For each trial, there was a control UV-untreated sample. UV treated and untreated samples were spread-plated in MYPG agar and incubated up to 10 days at $25^{\circ} \mathrm{C}$. CFU/mL were counted and survival graphs were made. Two Sample Welch $t$-test was applied with a significance level of $0.05(P<0.05)$, using $\mathrm{R}$ studio software (Version 3.6.1), to assess the differences between the two strains' inactivation profile for the same UV dose. Oneway analysis of variance (ANOVA) and post hoc Tukey test with a significance level of $0.001(P<0.001)$ were conducted to assess the differences among the different doses in microbial population reduction for both strains, using $\mathrm{R}$ studio software (Version 3.6. 1).

\section{Cleaning-In-Place (CIP) Tolerance Assay}

The tolerance of the filamentous yeast strain MS toward CIP treatments was compared to that of the budding yeast strain, S. lactativora, SL, both isolated from the RO membrane biofilms, by forming biofilms of single cultures on RO membrane coupons and exposing them to the different industrial CIP treatments on a lab-scale experiment. The coupons of $0.5 \times 1.5 \mathrm{~cm}$ were aseptically cut from an unused RO membrane, which had been stored at $4{ }^{\circ} \mathrm{C}$ in sodium metabisulfite solution $(1.0 \% \mathrm{w} / \mathrm{w})$. The coupons were flushed by pipetting three times from each side with autoclaved water to remove chemical traces and placed into sterile $1.5 \mathrm{~mL}$ eppendorf tubes. Inocula of $10^{5}$ cells $/ \mathrm{mL}$ were prepared for each strain with YPG broth as the suspension solution (see section "Heat Tolerance Assay"). For each isolate, $1 \mathrm{~mL}$ of the inoculum was poured into a tube, covering the coupon, and incubated for 1,5 , or 12 days at $25^{\circ} \mathrm{C}$. For each incubation period, a positive (inoculated) and a negative control (non-inoculated) were made for the two isolates (MS and $S L$ ) (Figure 1). In order to mimic a CIP program, the operating cleaning agents and time-temperature combinations from industrial CIP programs were used (Figure 1 and Table 1). The experiment consisted of four different treatments. The first involved only the application of the acidic solution and the second only the alkaline. The third treatment applied the acidic solution before the alkaline, while the fourth applied the alkaline 


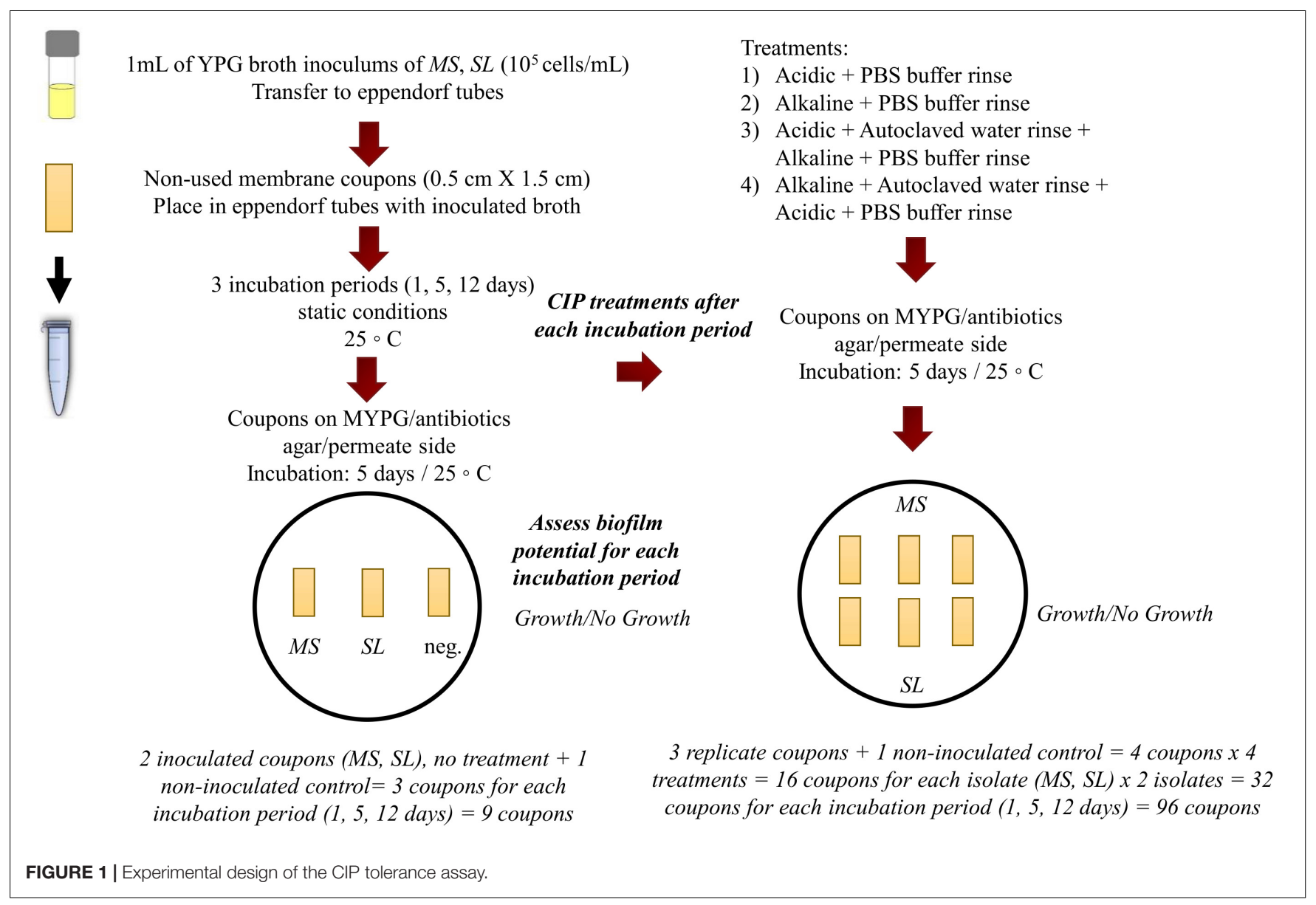

first, followed by the acidic. In the third and fourth treatment, there was a rinsing step by pipetting $1 \mathrm{~mL}$ of autoclaved water from each side of each coupon three times between the acidic and alkaline solution. At the end of all the treatments, there was a rinsing step by pipetting $1 \mathrm{~mL}$ of Phosphate Buffer Solution from each side of the coupon three times in a standardized manner before placing on agar (PBS: $8.00 \mathrm{~g} / \mathrm{L} \mathrm{NaCl}, 0.20 \mathrm{~g} / \mathrm{L} \mathrm{KCl}, 1.44 \mathrm{~g} / \mathrm{L}$ $\mathrm{Na}_{2} \mathrm{HPO}_{4}$ and $0.24 \mathrm{~g} / \mathrm{L}$ of $\mathrm{KH}_{2} \mathrm{PO}_{4}, \mathrm{pH} 7.4 \pm 0.2$ ). The CIP solutions were prepared according to the protocol of the producer using autoclaved water for dilution (Figure 1 and Table 1). For each treatment, three replicate coupons in inoculated YPG broth and one coupon in non-inoculated YPG broth (control) were made for each isolate ( $M S$ and $S L$ ) and for each incubation period (1, 5, and 12 days) (Figure $\mathbf{1})$.

The biofilm formation on the coupons was assessed by placing the inoculated coupons from each incubation period and isolate on MYPG/antibiotics agar along with the non-inoculated control with the permeate side facing downward. For the CIP tolerance assay, the triplicate coupons tested for each incubation period and isolate combination as well as the non-inoculated controls were exposed to the four different treatments (Figure 1). Eppendorf tubes were filled with $1 \mathrm{~mL}$ of the appropriate CIP solutions, corresponding to the treatment, and pre-heated to $50^{\circ} \mathrm{C}$ in heating blocks to mimic the temperature of the cleaning solutions during industrial CIP. The incubated RO membrane coupons were placed in these tubes and exposed to the various treatments. After each treatment the coupons were placed on MYPG/antibiotics agar supplemented with $0.1 \mathrm{~g} / \mathrm{L}$ chloramphenicol (Sigma C0378) and $0.5 \mathrm{~g} / \mathrm{L}$ chlortetracycline (Sigma C4881) with the permeate side facing downward. For both the biofilm forming potential and the CIP tolerance assays, the coupons were removed from the agar after 1 day and the plates were further incubated at $25^{\circ} \mathrm{C}$ for 5 days. Growth/no growth was macroscopically assessed on the agar plates after 5 days of incubation (Figure $\mathbf{1}$ and Table $\mathbf{1}$ ).

\section{Biofilm Formation on Polystyrene Microtiter Plates and Peg Lids}

Biofilm formation on flat-bottomed polystyrene microtiter plates (Thermo Scientific ${ }^{\mathrm{TM}}$ Nunc $^{\mathrm{TM}}$ MicroWell $^{\mathrm{TM}}$ ) was assessed using $0.1 \%$ Crystal Violet (CV) staining, indicative of biomass level, and tetrazolium salt (XTT) (Sigma, cat.no.X4251) staining with $1 \mu \mathrm{M}$ menadione (Sigma, cat.no.M5625), indicative of metabolic activity. Inocula of the filamentous yeast $S C$ and the budding yeast $S L$ were prepared $\left(10^{5}\right.$ cells $\left./ \mathrm{mL}\right)$ as in Section "Heat Tolerance Assay." Three different broth media were used for the final suspension: a low nutrient broth (R2B) containing $0.5 \mathrm{~g} / \mathrm{L}$ yeast extract, $0.5 \mathrm{~g} / \mathrm{L}$ proteose peptone, $0.5 \mathrm{~g} / \mathrm{L}$ casein hydrolysate, $0.5 \mathrm{~g} / \mathrm{L}$ glucose, $0.5 \mathrm{~g} / \mathrm{L}$ starch, $0.5 \mathrm{~g} / \mathrm{L}$ di-potassium 
TABLE 1 | The four different CIP treatments applied in the lab-scale experiment for the filamentous and budding yeast biofilm removal.

\begin{tabular}{|c|c|c|c|c|}
\hline \multicolumn{5}{|c|}{ CIP treatments } \\
\hline \multirow[t]{3}{*}{1} & \multicolumn{2}{|c|}{$\begin{array}{l}\text { Acidic cleaning solution (nitric acid and } \\
\text { citric acid) }\end{array}$} & \multirow{3}{*}{\multicolumn{2}{|c|}{ PBS buffer rinse }} \\
\hline & $45 \mathrm{~min} / 5$ & & & \\
\hline & $\mathrm{pH} 1.8$ & & & \\
\hline \multirow[t]{3}{*}{2} & $\begin{array}{r}\text { Alkaline cleaning solu } \\
\text { hydroxide, EDTA, } \\
\text { hydroxic }\end{array}$ & $\begin{array}{l}\text { n (potassium } \\
\text { a sodium }\end{array}$ & \multirow{3}{*}{\multicolumn{2}{|c|}{ PBS buffer rinse }} \\
\hline & $35 \mathrm{~min} / 5$ & & & \\
\hline & $\mathrm{pH} 11.0$ & & & \\
\hline 3 & $\begin{array}{l}\text { Acidic cleaning } \\
\text { solution (nitric acid } \\
\text { and citric acid) } \\
45 \mathrm{~min} / 50^{\circ} \mathrm{C} \\
\mathrm{pH} 1.8-2.0\end{array}$ & $\begin{array}{l}\text { Autoclaved } \\
\text { water rinse }\end{array}$ & $\begin{array}{c}\text { Alkaline cleaning } \\
\text { solution (potassium } \\
\text { hydroxide, EDTA, and } \\
\text { sodium hydroxide) } \\
35 \text { min } / 50^{\circ} \mathrm{C} \\
\text { pH } 11.0-11.5\end{array}$ & $\begin{array}{l}\text { PBS buffer } \\
\text { rinse }\end{array}$ \\
\hline 4 & $\begin{array}{c}\text { Alkaline cleaning } \\
\text { solution (potassium } \\
\text { hydroxide, EDTA, and } \\
\text { sodium hydroxide) } \\
35 \mathrm{~min} / 50^{\circ} \mathrm{C} \\
\mathrm{pH} 11.0-11.5\end{array}$ & $\begin{array}{l}\text { Autoclaved } \\
\text { water rinse }\end{array}$ & $\begin{array}{l}\text { Acidic cleaning } \\
\text { solution (nitric acid } \\
\text { and citric acid) } \\
45 \mathrm{~min} / 50^{\circ} \mathrm{C} \\
\mathrm{pH} 1.8-2.0\end{array}$ & $\begin{array}{l}\text { PBS buffer } \\
\text { rinse }\end{array}$ \\
\hline
\end{tabular}

phosphate, $0.024 \mathrm{~g} / \mathrm{L}$ magnesium sulfate, $0.3 \mathrm{~g} / \mathrm{L}$ sodium pyruvate $(\mathrm{pH} 7.2 \pm 0.2) ; \mathrm{R} 2 \mathrm{~B}+$ with $100 \mathrm{mg} / \mathrm{L}$ urea and lactose, respectively (approx. concentrations found in the twice filtered RO membrane permeate samples), and a high nutrient broth, YPG. Three incubation periods were applied: 1, 4, and 7 days. For each isolate, incubation period and staining method, a microtiter plate was inoculated with the three different media (200 $\mathrm{\mu L}$ /triplicate rows/eight wells). After 1, 4, and 7 days of incubation with shaking $\left(25^{\circ} \mathrm{C}, 140 \mathrm{rpm}\right)$, broth media were aspirated from the microplates, where after the microplates were washed $(200 \mu \mathrm{L} \mathrm{PBS} /$ three times) and stained with $0.1 \% \mathrm{CV}$ [protocol of Kirchhoff et al. (2017)] and $1 \mu \mathrm{M} \mathrm{XTT/menadione}$ [protocol of Pierce et al. (2008)]. For the $0.1 \% \mathrm{CV}$ assay, $125 \mu \mathrm{L}$ of $0.1 \% \mathrm{CV}$ solution were poured into each well and the microplates were incubated for $20 \mathrm{~min}$ in room temperature (RT). After three additional washing steps with $200 \mu \mathrm{L}$ PBS, the microplates were air-dried in inverted position at room temperature (RT) $\left(22^{\circ} \mathrm{C}\right)$ for $3 \mathrm{~h}$ and $200 \mu \mathrm{L} 30 \%(\mathrm{v} / \mathrm{v})$ acetic acid were added in each well. After $30 \mathrm{~min}$ incubation at RT, $150 \mu \mathrm{L}$ from each well were transferred to new microplates for each yeast strain and $\mathrm{OD}$ was measured at $600 \mathrm{~nm}$. For the XTT/menadione assay, $100 \mu \mathrm{L}$ of the prepared $1 \mu \mathrm{M}$ XTT/menadione solution were added to the microplates after draining. After incubation for $3 \mathrm{~h}$ at $25^{\circ} \mathrm{C} /$ dark conditions, $80 \mu \mathrm{L}$ from each well were transferred to new microplates for each yeast strain and the OD was measured at $490 \mathrm{~nm}$. OD was measured using the microtiter plate reader BioTeck ELx808. For both assays, the average OD value for each of the inoculated media wells was calculated by subtraction of the average OD value from the noninoculated media wells. Student's paired $t$-test was conducted with a significance level of $0.001(P<0.001)$ to assess the differences for each medium between the different incubation periods. R studio software (Version 3. 6. 1) was used for the statistical analysis.

Biofilm formation was also assessed on peg lids $\left(\mathrm{MBEC}^{\mathrm{TM}}\right.$ P\&G Assay/Innovotech) for both single and dual SC and SL yeast suspensions, applying three sonication times (10, 15, and $20 \mathrm{~min}$ ). The method was adapted from Harrison et al. (2010). Inocula of $10^{5}$ cells/mL were prepared for the single yeast and dual yeast biofilms, using YPG broth for the final suspension (see section "Heat Tolerance Assay"). For each sonication time: a microplate was prepared for the single yeast biofilm by inoculation of columns 1-6 with $150 \mu \mathrm{L}$ of SC inoculum and of columns 712 with $150 \mu \mathrm{L}$ of $S L$ inoculum (48 wells for each strain). For the dual yeast biofilm, $75 \mu \mathrm{L}$ of $S C$ and $S L$ inocula, respectively, were added to a microplate (final volume: $150 \mu \mathrm{L}$, columns 112,96 wells). The peg lids were inserted into the two inoculated microplates and incubated for $48 \mathrm{~h}$ at $25^{\circ} \mathrm{C}$ with shaking (140 rpm). After incubation, the peg lids were removed from the single and dual yeast microplates and rinsed by submerging subsequently for $1 \mathrm{~min}$ in two microplates containing Rinse Solution (PBS: $200 \mu \mathrm{L} /$ well), then submerged into microplates containing Recovery Solution (YPG broth: $200 \mu \mathrm{L} /$ well) and sonicated for $10 \mathrm{~min}$ (sonicator: Branson 2210R-MT Ultrasonic Cleaner, frequency: $40 \mathrm{kHz}$ ). The same procedure was repeated for the 15- and 20- min sonication time. After each sonication time, $20 \mu \mathrm{L}$ from 12 wells of the single SC sonicated microplate were diluted into the first row of a microplate for dilutions, containing $180 \mu \mathrm{L}$ of Recovery solution. Four dilutions were made in total (A-D/columns 1-12). Control wells were also prepared, using non-inoculated YPG broth. $10 \mu \mathrm{L}$ from each well (rows A-D) and from the control wells were spotted on YPG agar. The same procedure was repeated for $S L$ and for the dual biofilm microplate. The YPG agar plates were incubated at $25^{\circ} \mathrm{C}$ for $2-$ 3 days. $\log _{10}(\mathrm{CFU} / \mathrm{mL})$ was calculated for the single and dual biofilms for the three different sonication times, by calculating the average of 12 wells from the colonies of countable dilutions. Student's paired $t$-test was conducted to assess individually the differences for the $S C$ single and the dual SC\&SL biofilm cultures for the different sonication times with a significance level of 0.001 $(P<0.001)$. Two Sample Welch $t$-test was applied to assess the differences between SC single and the dual SC\&SL biofilm cultures for the same sonication time with a significance level of $0.001(P<0.001)$. R studio software (Version 3.6. 1) was used for the statistical analysis.

\section{RESULTS}

\section{Macroscopic and Microscopic Analysis of the Filamentous Yeast Isolates}

On MEA agar, after 12 days incubation at $25^{\circ} \mathrm{C}, S C$ colonies were circular with a 2-7 $\mathrm{mm}$ diameter, glassy, tough, hirsute, white, convex, and filiform with 1-4 $\mathrm{mm}$ mycelium length, while MS colonies were circular with a 1-3 $\mathrm{mm}$ diameter, butyrous, glistening, soft, whitish, convex, and filiform with $1 \mathrm{~mm}$ mycelium. Overall, MS developed a much shorter mycelium than SC. On MEA agar, after 4 days of incubation at $25^{\circ} \mathrm{C}$, the budding yeast $S L$ strain formed circular, glistening, butyrous, 
creamy colonies without mycelium and approx. $2 \mathrm{~mm}$ in diameter (Table 2). Microscopically, SC and MS developed septate branching hyphae that elongated by continuous growth of the hyphal tip followed by formation of septa after 6 days of incubation in YPG broth. Septa were refractive and thick with little or no constriction and arthroconidia were rectangularrounded. They both had large vacuoles, while MS developed swollen terminal cells or semi-circle cells (Figure 2). Cell size was measured for at least 20 cells for each yeast strain in the microscope and the minimum-maximum values were 10 and $350 \mu \mathrm{m}$ in length and 3 and $7.5 \mu \mathrm{m}$ in width. SL cells were ovoidellipsoid with minimum-maximum cell values of 4 and $6 \mu \mathrm{m}$ in length and 2 and $4 \mu \mathrm{m}$ in width. Multilateral budding on a narrow base was observed for $S L$ (Table 2).

\section{Physiological and Biochemical Tests}

Both SC and MS grew at all temperatures tested in YPG broth. They could not ferment the sugars tested (glucose, sucrose, lactose, galactose, raffinose, trehalose, and maltose), but they assimilated several carbon compounds, corresponding to the species' definition of Sybren De Hoog and Smith (2011b) for
S. clavata and of Sybren De Hoog and Smith (2011a) for M. spicifer. Christensen's urea broth reaction for urease activity was negative for both isolates (Table 3).

\section{Growth in Twice Filtrated-RO Permeate Water}

Although both filamentous yeast isolates were negative for the Christensen's urea broth reaction, they both grew in the twice RO-filtrated permeate water containing urea and decreased the level of urea by more than $50 \mathrm{mg} / \mathrm{L}$ while producing ammonia (Table 4).

\section{Heat Tolerance Assay}

The initial inoculum for SC (S. clavata) and MS (M. spicifer) was approx. $10^{5}$ cells $/ \mathrm{mL}$ (Figure 3 ). The cell suspensions of $S C$ and $M S$ were tolerant to heat treatment at $60^{\circ} \mathrm{C}$, being reduced less than 2 and $3 \log _{10}(\mathrm{CFU} / \mathrm{mL})$, respectively, after 20 min SC was still detectable after exposure at $70^{\circ} \mathrm{C}$ for up to $10 \mathrm{~min}$, while $M S$ became undetectable after $5 \mathrm{~min}$. At $80^{\circ} \mathrm{C}$, $S C$ also became undetectable within $5 \mathrm{~min}$. The $D$-value for $S C$

TABLE 2 | The selected strains for the different physiological-biochemical tests and stress tolerance assays.

\begin{tabular}{|c|c|c|}
\hline Isolates & Colony morphology & Colony morphology \\
\hline $\begin{array}{l}\text { SC Saprochaete clavata } \\
\text { Synonym: Geotrichum } \\
\text { clavatum (Sybren De Hoog } \\
\text { and Smith, 2011b) }\end{array}$ & & $\begin{array}{l}\text { Circular Glassy Convex } \\
\text { Tough White Mycelium }\end{array}$ \\
\hline
\end{tabular}

MS Magnusiomyces spicifer

Synonym: Dipodascus spicifer (Sybren De Hoog and Smith, 2011a)
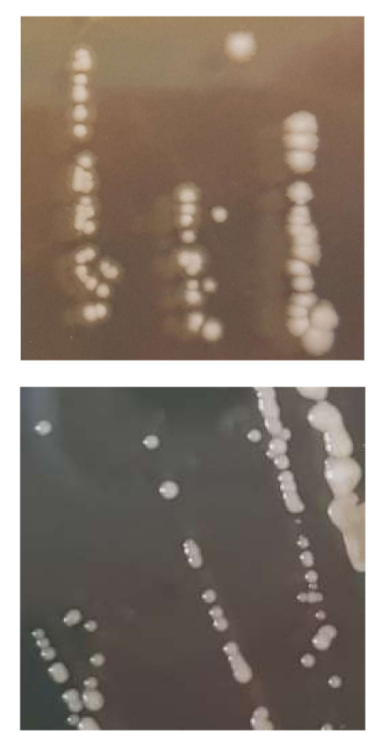

SL Sporopachydermia lactativora lactativorus (Lachance, 2011)
Synonym: Cryptococcus
Circular Butyrous Convex Soft Whitish Mycelium

Cell morphology $1,000 x$ magnification
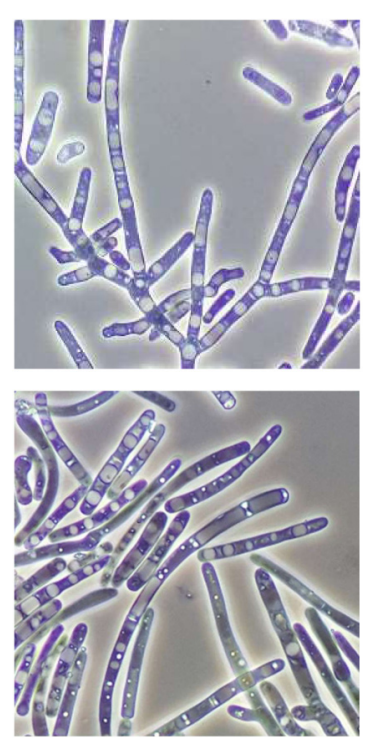

Circular Butyrous Glistening Convex Creamy

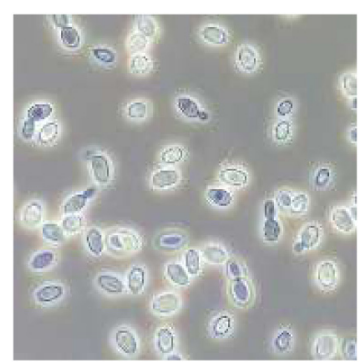

Cell morphology

Anamorph of

Magnusiomyces spp.

Asexual reproduction:

True hyphae branched,

disarticulating into

arthroconidia.

S. clavata and M. spicifer: colonies in MEA agar/12 days incubation/25 $\mathrm{C}$, cells in YPG broth/12 days incubation/25 $\mathrm{C} /$ shaking at 225 rpm, Sporopachydermia lactativora: colonies and cells in MEA agar/4 days $/ 25^{\circ} \mathrm{C}$. 


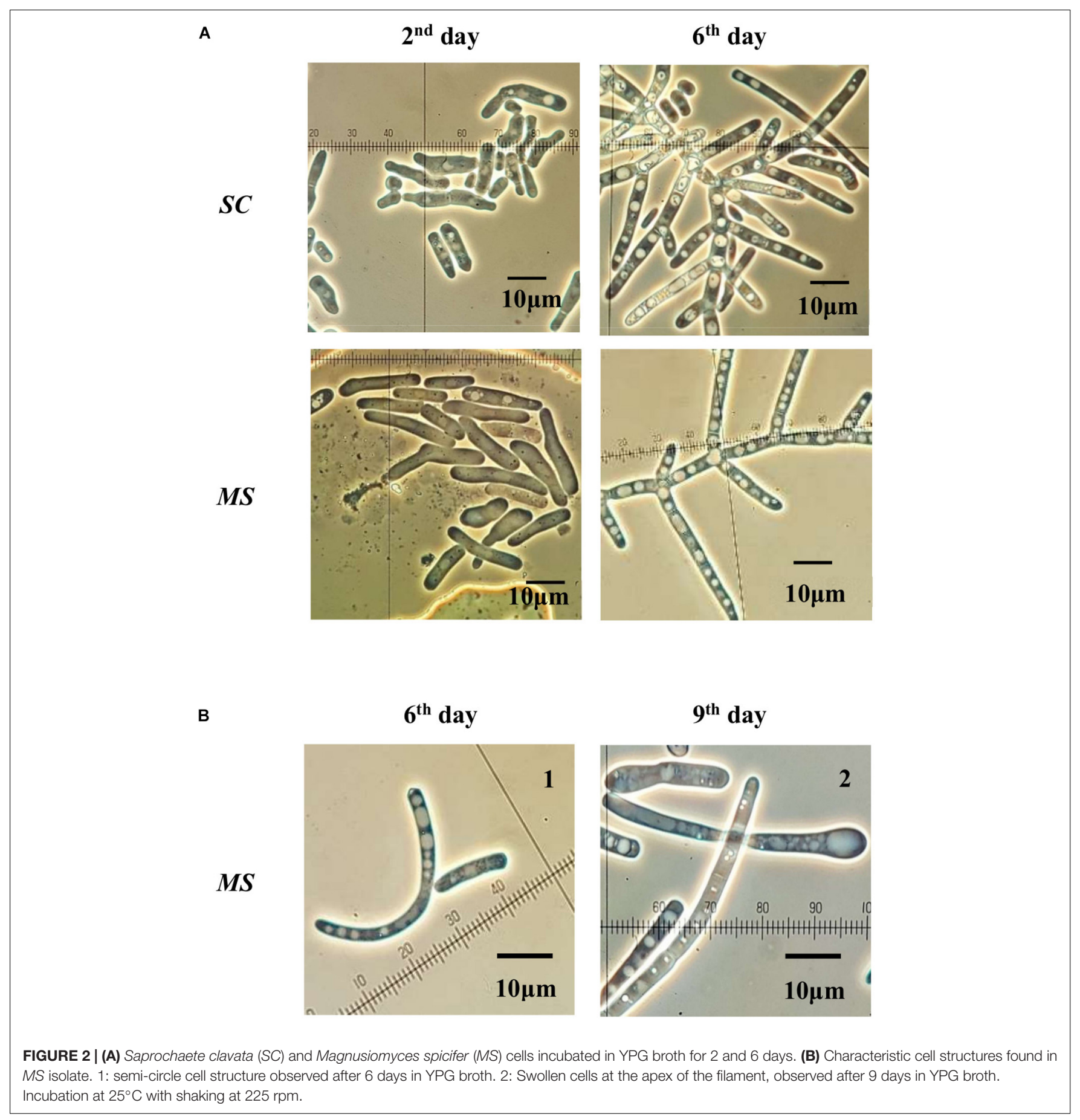

at $60^{\circ} \mathrm{C}$ was $D_{60}{ }^{\circ} \mathrm{C}=16.37 \mathrm{~min}$, while the $D$-value of $M S$ was $D_{60}{ }^{\circ} \mathrm{C}=7.24 \mathrm{~min}$.

\section{UV-C Light Treatment}

The survival bars in $\log _{10}(\mathrm{CFU} / \mathrm{mL})$ for $M S$ and $S C$, respectively, for the different UV doses are presented in Figure 4. Both isolates exhibited high tolerance to UV-C treatment. Exposure to $10 \mathrm{~mJ} / \mathrm{cm}^{2}$ resulted in less than $1.00 \log _{10}(\mathrm{CFU} / \mathrm{mL})$ and exposure to $20 \mathrm{~mJ} / \mathrm{cm}^{2}$ in less than $4.00 \log _{10}(\mathrm{CFU} / \mathrm{mL})$ reduction. A UV dose of $40 \mathrm{~mJ} / \mathrm{cm}^{2}$, usually applied in the industrial UV-C water treatment lines, resulted in approx. 4.00 $\log _{10}(\mathrm{CFU} / \mathrm{mL})$ reduction for $M S$ and $5.00 \log _{10}(\mathrm{CFU} / \mathrm{mL})$ reduction for $S C$. Exposure to $60 \mathrm{~mJ} / \mathrm{cm}^{2}$ resulted in approx. 1 $\log _{10}(\mathrm{CFU} / \mathrm{mL})$ further reduction for both strains. There was no higher decrease in population by applying $100 \mathrm{~mJ} / \mathrm{cm}^{2}$. After doses of 200 and $400 \mathrm{~mJ} / \mathrm{cm}^{2}$, applied in two of the trials, sporadic survivors were found (Data not shown). Two Sample Welch $t$-test with a significance level of 0.05 showed that the differences in 
TABLE 3 | Assimilation of carbon compounds and nitrate*, urease activity ${ }^{\star \star}$ and sugar fermentation ${ }^{\star \star \star}$ for S. clavata and M. spicifer.

\begin{tabular}{|c|c|c|c|c|c|c|c|c|c|}
\hline \multirow[b]{2}{*}{ Strains } & \multicolumn{4}{|c|}{ Assimilation of carbon compounds } & \multicolumn{5}{|c|}{ Sugar fermentation } \\
\hline & $\begin{array}{l}\text { S. clavata } \\
\text { (This study) }\end{array}$ & $\begin{array}{c}\text { S. clavata } \\
\text { (Sybren De } \\
\text { Hoog and } \\
\text { Smith, 2011b) }\end{array}$ & $\begin{array}{l}\text { M. spicifer } \\
\text { (This study) }\end{array}$ & $\begin{array}{c}\text { M. spicifer } \\
\text { (Sybren De } \\
\text { Hoog and } \\
\text { Smith, 2011a) }\end{array}$ & $\begin{array}{l}\text { S. clavata } \\
\text { (This study) }\end{array}$ & $\begin{array}{c}\text { S. clavata } \\
\text { (Sybren De } \\
\text { Hoog and } \\
\text { Smith, 2011b) }\end{array}$ & $\begin{array}{l}\text { M. spicifer } \\
\text { (This study) }\end{array}$ & $\begin{array}{c}\text { M. spicifer } \\
\text { (Sybren De } \\
\text { Hoog and } \\
\text { Smith, 2011a) }\end{array}$ & $\begin{array}{l}\text { S. clavata } \\
\text { (This study) }\end{array}$ \\
\hline 2-5 Glucose & + & + & + & + & - & - & - & - & - \\
\hline Sucrose & - & - & - & - & - & - & - & - & - \\
\hline Lactose & - & - & - & - & - & - & - & - & - \\
\hline Galactose & + & + & + & + & - & - & - & - & - \\
\hline Raffinose & - & - & - & - & - & - & - & - & - \\
\hline Trehalose & - & - & - & - & - & - & - & - & - \\
\hline Maltose & - & - & - & - & - & - & - & - & - \\
\hline D-Xylose & Weak & - & + & + & & & & & \\
\hline L-Sorbose & Slow & + & Slow & + & & & & & \\
\hline Cellobiose & + & + & Slow & + & & & & & \\
\hline Salicin & + & + & Slow & + & & & & & \\
\hline DL-Lactate & Weak & +Meak & Weak & + & & & & & \\
\hline Succinate & Weak & + & Weak & + & & & & & \\
\hline Citrate & Weak & + & Weak & + & & & & & \\
\hline Nitrate & - & - & - & - & & & & & \\
\hline $\begin{array}{l}\text { Urease activity } \\
\text { (Christensen's urea } \\
\text { broth) }\end{array}$ & - & - & - & - & & & & & \\
\hline
\end{tabular}

Triplicates were made for each compound and strain $(n=3){ }^{*}$ Tubes were assessed after 1, 2, 3, and 4 weeks with the Wickerham card. +: growth after 1-2 weeks. Slow:

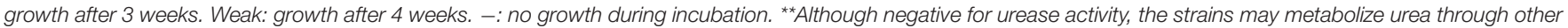
pathways. ${ }^{* *} /$ Inverted Durham tubes were assessed for gas accumulation after 1, 2, 3, and 4 weeks. -: no accumulation of gas.

population level reduction between the two strains for each dose applied were no significant $(P>0.05)$. One-way ANOVA and post hoc Tukey test conducted, showed that for both strains, there was significant reduction in microbial population after 20 and $40 \mathrm{~mJ} / \mathrm{cm}^{2}(P<0.001)$, compared to dose 0 . However, there was not significant difference in the reduction among the doses of 40 , 60 , and $100 \mathrm{~mJ} / \mathrm{cm}^{2}(P>0.001)$.

\section{CIP Tolerance Assay}

Biofilms developed already after the 1st day on the membrane coupons for both the filamentous (MS) and the budding (SL) yeast isolate, and later increased further in biomass, as seen in the upper row of Table 5. Exposure to individual and combined treatments with the alkaline and the acidic cleaning solution did not eliminate the biofilms of neither SL nor MS strain. However, the combined treatments were more effective than the individual ones in biofilm removal, especially after 1 day of

TABLE 4 | Urea reduction and ammonia production in twice RO-filtrated permeate water by growth of the two filamentous species.

\begin{tabular}{lccc}
\hline & $\begin{array}{c}\text { Control (not } \\
\text { inoculated RO } \\
\text { water) }\end{array}$ & $\begin{array}{c}\text { Saprochaete } \\
\text { clavata in RO } \\
\text { water }\end{array}$ & $\begin{array}{c}\text { Magnusiomyces } \\
\text { spicifer in RO } \\
\text { water }\end{array}$ \\
\hline Urea* $^{*}(\mathrm{mg} / \mathrm{L})$ & 130.7 & 78.2 & 66.9 \\
$\mathrm{Ammonia}^{*}(\mathrm{mg} / \mathrm{L})$ & 0.0 & 24.7 & 35.2 \\
\hline
\end{tabular}

*Detection limit: ammonia: 2.8 ppm, urea: 5.1 ppm. coupon incubation while the more mature biofilms were difficult to eradicate. This was especially true for the SL. Changing the succession of the acidic and alkaline solution during CIP did not seem to improve biofilm removal.

\section{Biofilm Formation on Polystyrene Microplates}

Saprochaete clavata created strong biofilm in the flat-bottomed polystyrene microtiter well assay in all the different media, according to both staining methods used (Figure 5). The biomass (CV) increased significantly from the first to the fourth day of incubation in all the different media (Figures 5 A,C,D) $(P<0.001)$, while at the same time the metabolic activity (XTT) decreased significantly in R2B + and R2B (Figures 5B,D) $(P<0.001)$. In XTT/YPG, there were no statistically significant differences found throughout incubation (Figure 5F) $(P<0.001)$. From Days 4 to 7 , both biomass $(\mathrm{CV})$ and metabolic activity (XTT) decreased, indicating cell death. SL did not attach and create biofilms on polystyrene. OD was between $0.000-0.092$ in $0.1 \% \mathrm{CV}$ and between $0.000-0.058$ in XTT/menadione for the different media and incubation days.

The biofilm formation on peg lids also supported that the filamentous $S C$ had the ability to form biofilm, while no biofilm formation was detected for the tested budding yeast $S L$ (Table 6). The filamentous yeast SC biofilm had high recovery numbers for all tested sonication times, while $S L$ was below the detection limit of the method (100 cells $/ \mathrm{mL})$. The biofilm recovery numbers 


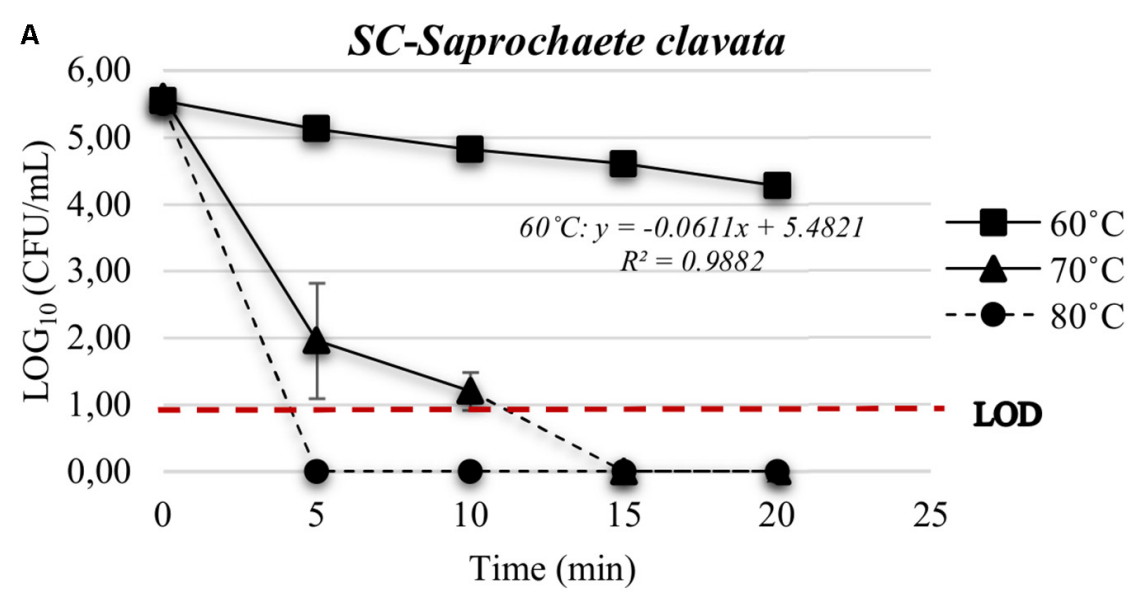

B

MS-Magnusiomyces spicifer

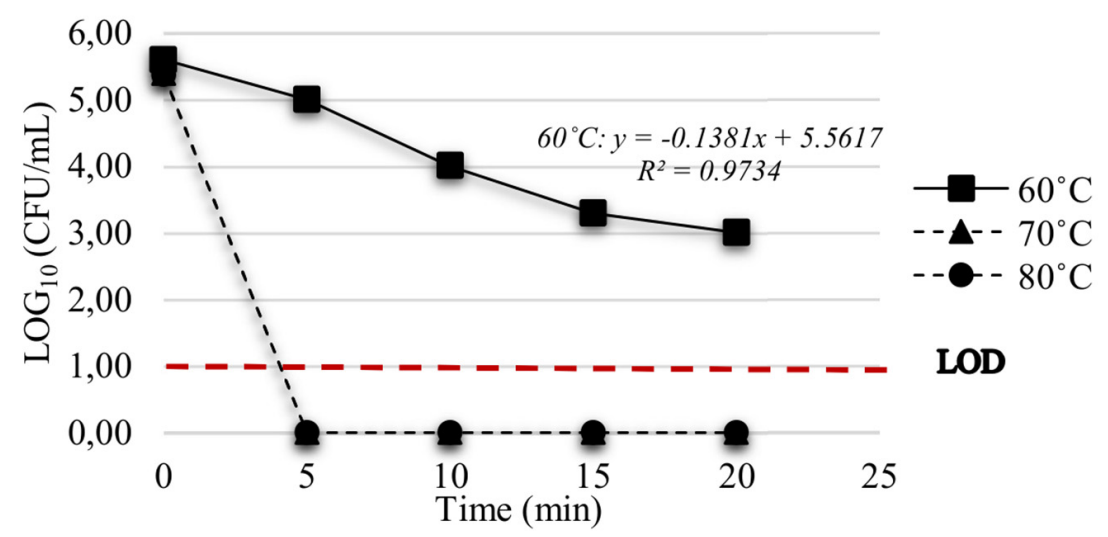

FIGURE 3 | Heat inactivation of (A) S. clavata (SC) and (B) M. spicifer (MS) in SPS at 60, 70, and $80^{\circ} \mathrm{C}$ for 5,10 , 15 , and 20 min. Phantom lines indicate that population level was below the LOD (10 cells $/ \mathrm{mL}$ ). Mean value and standard deviation were calculated from three technical replicates for each temperature-time interval and strain $(n=3)$. Medium: MYPG agar. Incubation: 10 days $/ 25^{\circ} \mathrm{C}$.

were statistically significantly lower in the dual SC\&SL biofilm compared to the single $S C$ biofilm for 10 and $15 \min (P<0.001)$. However, no differences were observed between the single and the dual biofilm after $20 \mathrm{~min}(P>0.001)$. Regarding the different sonication times, 15 min were more efficient in biofilm cell recovery numbers. The decrease in cell recovery numbers after 20 min could be due to inactivation of the yeast after prolonged sonication at $40 \mathrm{kHz}$.

\section{DISCUSSION}

\section{Isolation and Characterization of the Filamentous Yeast Isolates}

The filamentous yeast species S. clavata and M. spicifer dominated the biofilm communities on the retentate and permeate side of $\mathrm{RO}$ membranes used in a dairy operation line for treating whey water. These filamentous yeasts were isolated after CIP application on several occasions from elements having been in use for 6 months and up to 4 years. Interestingly, the biofilms on the permeate side of most of these elements, consisted exclusively of the filamentous yeast strains. Since biofouling can interfere with flux and may potentially affect the quality of the retentate and permeate, there is clearly an interest in characterizing these yeasts and obtain an understanding of their persistence and role. It has already been established that they may cover large areas and still go relatively unnoticed unless selective media are used for their detection, since they are often present in lower numbers and grow slower than bacteria, causing them to be out-grown on non-selective media (Stoica et al., 2018; Vitzilaiou et al., 2019).

The yeasts $S$. clavata and $M$. spicifer have a high degree of similarity in physiology, cell-colony morphology and biochemical profile. They both developed mycelium on agar after long incubation and their cells elongated and created septate branching hyphae. They had the same temperature growth range and assimilated the same carbon compounds, while they did not assimilate nitrate. According to taxonomy, they are closely related species. Saprochaete and Magnusiomyces 


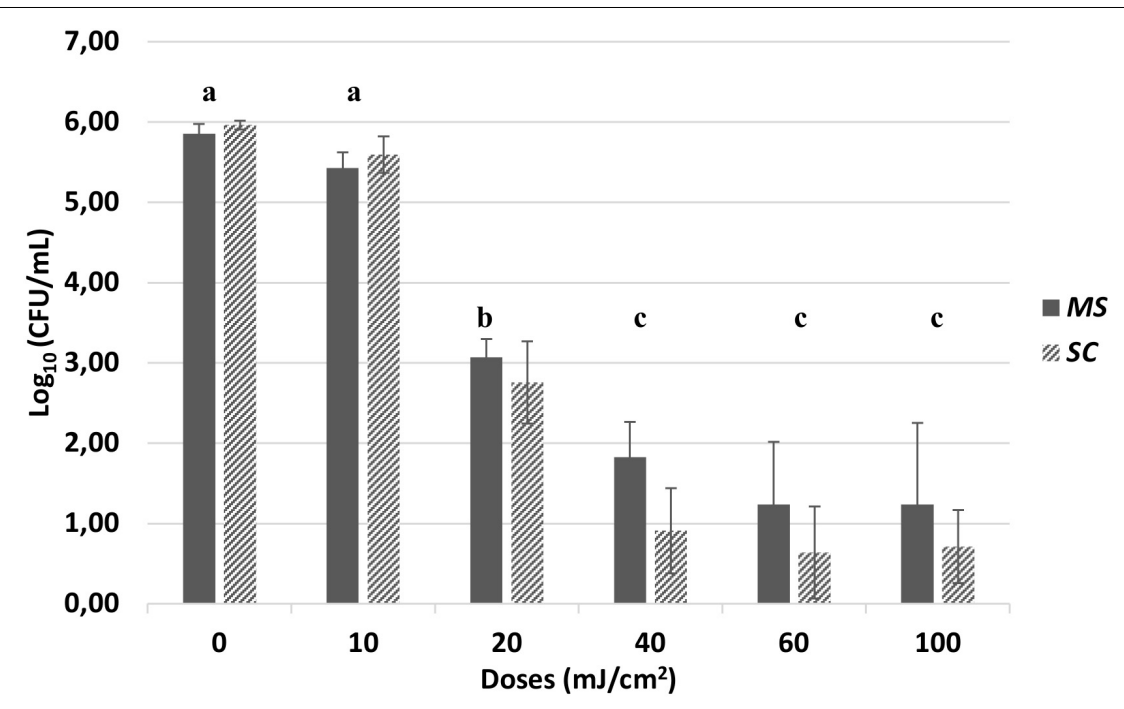

FIGURE 4 | Population level in Log $_{10}$ [CFU/mL of M. spicifer (MS) and S. clavata (SC)] after exposure to UV doses of 0, 10, 20, 40,60, and 100 mJ/cm². Inoculation level: $10^{6}$ cells $/ \mathrm{mL}$. LOD: $1 \mathrm{CFU} / \mathrm{mL}$. The average and standard deviation has been calculated from four different trials with two replicates within each trial $(n=8)$. Sporadic survivors were found when applying 200 and $400 \mathrm{~mJ} / \mathrm{cm}^{2}$ (Data not shown). No significant differences were found $(P>0.05)$ between the two strains for each dose. The different letters indicate the significant differences in microbial reduction among the different doses for both isolates $(P<0.001)$. Agar medium: MYPG, 10 days incubation at $25^{\circ} \mathrm{C}$.

genera belong to the same phylum, class and order (Ascomycota, Saccharomycetes, and Saccharomycetales). Saprochaete is the anamorph of Magnusiomyces and Magnusiomyces and Saprochaete are sister genera to Galactomyces, Dipodascus and their anamorph Geotrichum (Sybren De Hoog and Smith, 2004, 2011a,b). The differentiation between Saprochaete and Magnusiomyces is difficult as also reported by Del Principe et al. (2016). The identification results in the NCBI Database, based on $26 \mathrm{~S}$ and ITS rRNA sequencing, were often giving similar matches in terms of (\%) coverage, (\%) similarity rates and $E$-values for $M$. spicifer and S. clavata. Thus, we believe that there is a need to increase the diversification of the existing databases on fungal species, as well as to develop new methods for fungal species identification.

\section{Urea Metabolism}

Ultrafiltration followed by RO membrane filtration will, in theory, remove the fouling agents and microbial cells, while small molecules may pass through the membrane pores. Urea from whey can pass the RO membranes (Skou et al., 2017, 2018) and may therefore be a source of nitrogen and energy for some microorganisms in the low-nutrient RO permeate. The filamentous yeast strains, S. clavata and M. spicifer, were initially tested for urease using Christensen's Urea Broth assay. The principle is based on the presence of urease, which converts urea in a one-step reaction producing ammonia thereby increasing the $\mathrm{pH}$ of the broth resulting in a color change. Rapid ureasepositive organisms can change the medium's color to pink within 2-4 h (Kurtzman et al., 2011). Both the filamentous yeast strains tested were negative in this assay. However, when grown in the twice RO-filtrated permeate water, they both metabolized urea and produced ammonia. Both M. spicifer and
S. clavata belong to Hemiascomycetes, which include one class and order (Saccharomycetes and Saccharomycetales). It has been observed that yeasts belonging to Hemiascomycetes contain urea amidolyase, instead of urease (Souciet et al., 2000; Sybren De Hoog and Smith, 2004, 2011a,b; Strope et al., 2011). Urea amidolyase is an enzyme that breaks down urea into ammonia and carbon dioxide through a two-step process. Although a slower mechanism of urea metabolism, it may be advantageous in some settings, since urea amidolyase, in contrast to urease, is not dependent on the concentration of $\mathrm{Ni}^{2+}$ and $\mathrm{Co}^{2+}$ (Booth and Vishniac, 1987; Navarathna et al., 2010; Strope et al., 2011).

\section{Heat Tolerance Assay in Saline Peptone Solution}

The $D$-values can be affected by several parameters such as strain differences, growth phase and conditions prior to heating as well as the matrix and recovery methods (Doyle et al., 2001) and comparison between different experiments should therefore be done with caution. Nevertheless, if the $D$-values of the $S$. clavata strain $\left(D_{60}{ }^{\circ} \mathrm{C}=16.37 \mathrm{~min}\right)$ and the $M$. spicifer $\left(D_{60}{ }^{\circ} \mathrm{C}=7.24 \mathrm{~min}\right)$ are compared with previously published average values for common bacterial foodborne pathogens such as Listeria monocytogenes $\left(D_{60}{ }^{\circ} \mathrm{C}=4.56 \mathrm{~min}\right)$ and $E$. coli O157:H7 $\left(D_{60}{ }^{\circ} \mathrm{C}=3.37 \mathrm{~min}\right)$ (Buzrul and Alpas, 2007) in a similar matrix ( $1 \%$ peptone solution), both filamentous yeast strains seem markedly more tolerant to heat treatment. The more heat resistant $S$. clavata has three to four times higher $D_{60}{ }^{\circ} \mathrm{C}$ than the strains of $L$. monocytogenes and four times or more than the strains of E. coli O157:H7 reported by Buzrul and Alpas (2007). Although the two yeasts were very close in taxonomy, morphology and physiology, S. clavata 
TABLE 5 | Tolerance toward different CIP treatments at $50^{\circ} \mathrm{C}$ of single filamentous and budding yeast biofilms, formed on $\mathrm{RO}$ membrane coupons.

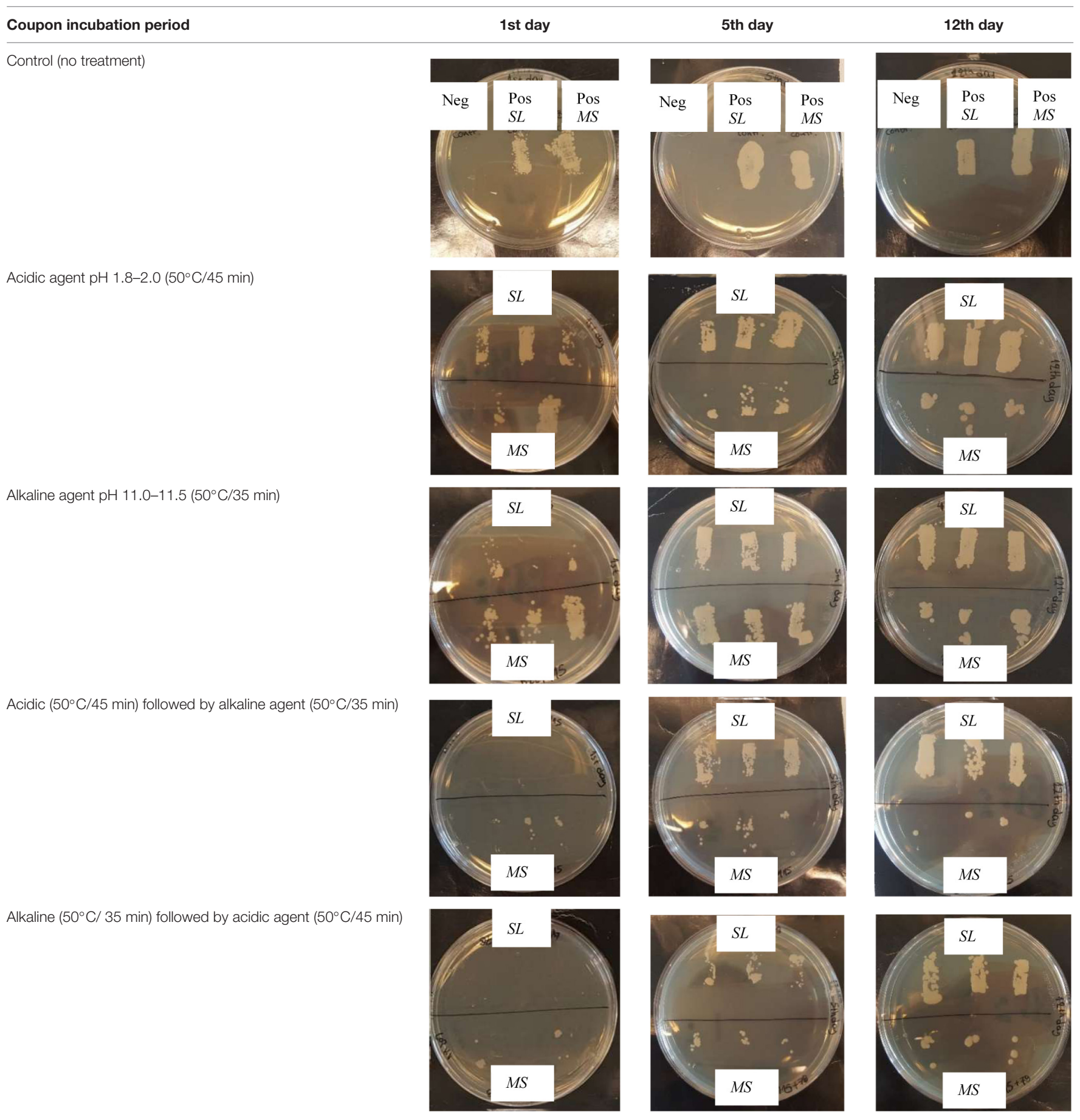

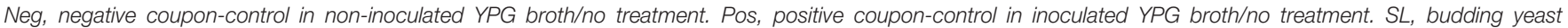
(S. lactativora); MS, filamentous yeast (M. spicifer). Triplicates were made for each CIP treatment and strain. Initial inoculum: $10^{5}$ cells/mL. Agar plates' incubation: MYPG/antibiotics, 12 days, $25^{\circ} \mathrm{C}$. Negative controls for CIP treatments for rows 2-5 not shown.

was markedly more heat tolerant, indicating that important functional characteristics may vary considerably.

In terms of the CIP programs applied in this type of food industry, cleaning solutions and water flushes are often applied at a temperature of $50^{\circ} \mathrm{C}$ for $35-45 \mathrm{~min}$ for each step (Table 1), since most of the RO membrane elements used in these lines cannot stand higher temperatures (Stoica et al., 2018; Vitzilaiou et al., 2019). Although the CIP cleaning may last more than $2 \mathrm{~h}$, our results indicate that a temperature of $50^{\circ} \mathrm{C}$ will not ensure inactivation of biofilms containing these yeasts. According to the assay, temperatures of $70^{\circ} \mathrm{C}$ and higher for more than $10 \mathrm{~min}$ ensured at least $4 \mathrm{log}$ reductions. This could explain previously 


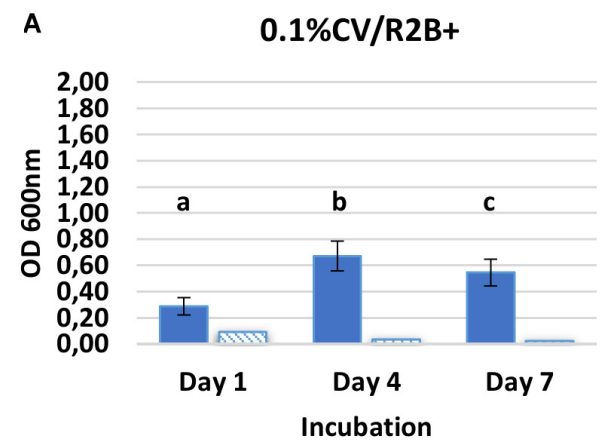

nilamentous $\quad$ budding

C

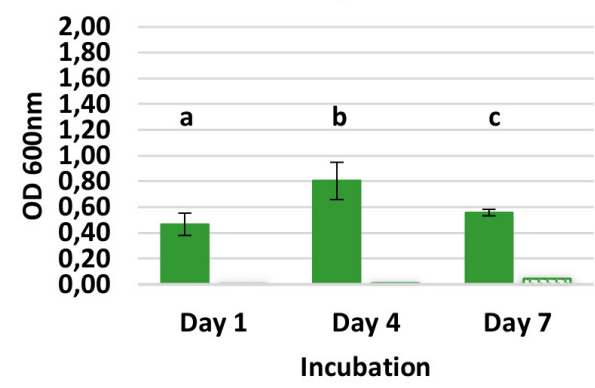

filamentous oudding

E

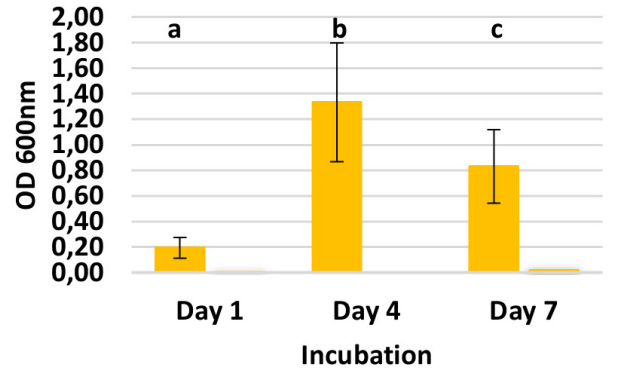

filamentous budding
B

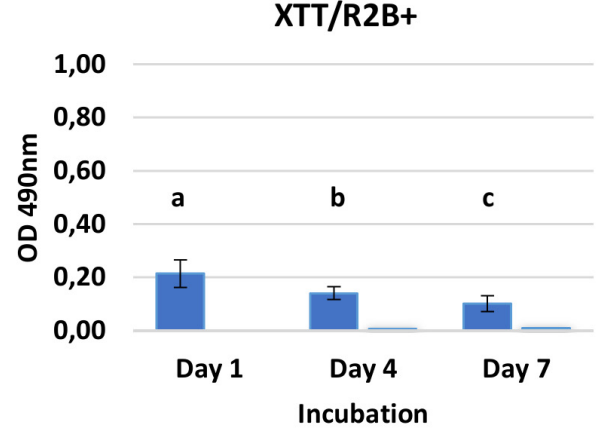

filamentous

จ budding

D
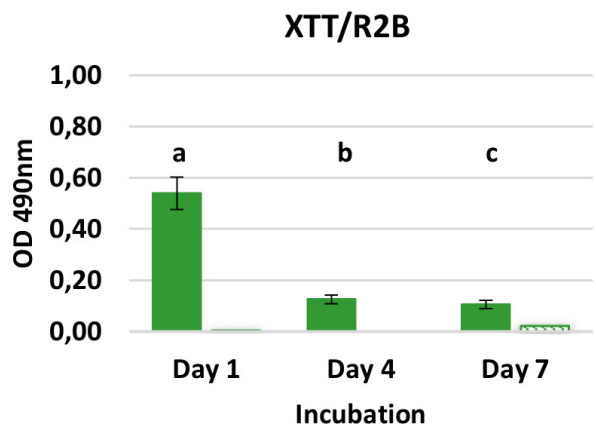

filamentous $\$$ budding

$\mathbf{F}$

XTT/YPG

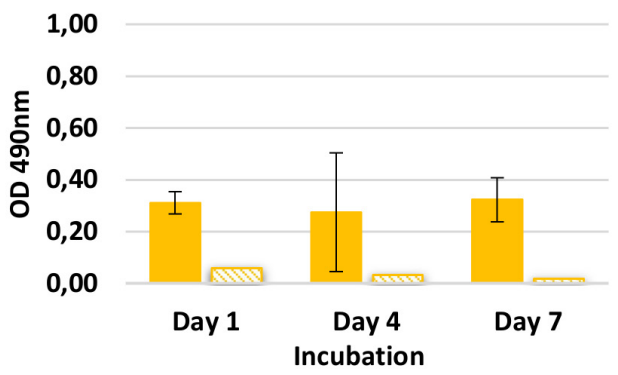

filamentous budding

FIGURE 5 | Biofilm quantification of the filamentous yeast S. clavata and budding yeast S. lactativora using $0.1 \%$ CV and XTT/menadione stains in R2B + with urea and lactose (A,B), R2B (C,D), and YPG broth (E,F) after 1, 4, and 7 days of incubation $\left(25^{\circ} \mathrm{C}\right.$, shaking at $\left.140 \mathrm{rpm}\right)$. Mean value and standard deviation are calculated from 24 replicate wells for each medium. Significant differences for the filamentous yeast are presented for each graph with the different letters (a, b, c) $(P<0.001)$.

reported observations (Stoica et al., 2018; Vitzilaiou et al., 2019) from some heat tolerant elements being exposed to high heat $\left(78^{\circ} \mathrm{C} / 20 \mathrm{~min}\right)$ where no filamentous yeasts were detected.

\section{UV-C Tolerance}

A UV dose of $40 \mathrm{~mJ} / \mathrm{cm}^{2}$, usually applied in industrial scale water treatment, reduced the population of both $S$. clavata and $M$. spicifer by approx. $4 \log _{10}(\mathrm{CFU} / \mathrm{mL})$, but not below the LOD of the method. Moreover, higher doses of 60 and $100 \mathrm{~mJ} / \mathrm{cm}^{2}$, did not result in significantly higher inactivation, according to one way ANOVA conducted $(P>0.001)$. Bowker et al. (2011), using a similar UV-C LED set-up at $255 \mathrm{~nm}$ and phosphate buffer, needed a dose of $9 \mathrm{~mJ} / \mathrm{cm}^{2}$ to decrease a $10^{8}$ cells $/ \mathrm{mL}$ inoculum of $E$. coli by $2.7 \log _{10}(\mathrm{CFU} / \mathrm{mL})$. In this study, doses of $20-40 \mathrm{~mJ} / \mathrm{cm}^{2}$ were needed to obtain the same decrease in the filamentous yeast isolates. UV-C is a well-recognized treatment for water and there is extensive information available for bacteria and viruses as summarized in several reviews (Song et al., 2016; Li et al., 2019). However, there is limited knowledge on fungal tolerance toward UV treatments and the results reported here expands our knowledge of the sensitivity of filamentous yeast. 
TABLE 6 | Biofilm cell counts on peg lids obtained from Recovery Solution (YPG) at 10-, 15-, and 20-min sonication time for S. clavata (SC), S. lactativora (SL) single biofilms, and SC/SL dual biofilms.

\begin{tabular}{|c|c|c|c|}
\hline \multirow[t]{2}{*}{ Sonication time (min) } & 10 & 15 & 20 \\
\hline & \multicolumn{3}{|c|}{$\log _{10}(\mathrm{CFU} / \mathrm{ml})$} \\
\hline SC (Single biofilm) & $4.73 \pm 0.17^{a}$ & $5.25 \pm 0.22^{b}$ & $4.16 \pm 0.20^{c}$ \\
\hline SL (Single biofilm) & $<L O D$ & $<L O D$ & $<L O D$ \\
\hline SC\&SL (Dual biofilm) & $4.33 \pm 0.11^{d}$ & $4.45 \pm 0.12^{d}$ & $3.90 \pm 0.34^{\mathrm{c}}$ \\
\hline
\end{tabular}

Data from control wells was negative (not shown). Mean values and standard deviation were calculated from 12 replicates. Significant differences within SC and SC\&SL biofilms for the different sonication times and between SC and SC\&SL biofilms for the same sonication time are indicated with different letters $(a, b, c, d)$ $(P<0.001)$. LOD was $100 \mathrm{cells} / \mathrm{mL}$.

\section{Biofilm Tolerance to CIP Assay}

The budding yeast strain S. lactativora $(S L)$ was found in some of the biofilm structures on the RO membrane elements together with the filamentous yeasts, but in lower numbers. When this strain and the filamentous strain, $M$. spicifer $(M S)$, were tested for their tolerance toward CIP treatments, by forming biofilms on RO membrane coupons and exposing them to the industrial CIP solutions, they both displayed a considerable tolerance. Combination treatments inactivated more cells than acid or alkaline solutions individually. No difference in survival was found due to the order of application of the acidic and the alkaline solution. In production lines, the chemically dependent effect of the CIP solutions will only be exerted on the retentate side of the RO. According to our previous work examining RO elements from production, filamentous yeasts were detected on both the retentate and the permeate side when CIP treatments applied the acidic solution first, followed by the alkaline while yeasts were only detected on the retentate surface of one RO element in which the alkaline solution was applied first and the acidic at the end (Stoica et al., 2018; Vitzilaiou et al., 2019). Since the inactivating effect of the combinations seems to be similar, it could indicate that the membranes become more prone to hyphae breakthrough when the treatment finishes with alkali and it has been suggested that alkaline solutions can lead to membrane pore expansion (Simon et al., 2013). This merits further investigation.

The biofilm of the budding yeast isolate during the membrane coupon experiments was less affected by the CIP treatment in the laboratory-based experiments. However, the filamentous yeasts found to be the dominant microorganisms on the retentate side of RO membrane elements from industry and the only biofilm former on the RO permeate surfaces after CIP. When the individual cultures of the filamentous and the budding yeast isolate were tested for biofilm formation on polystyrene flatbottomed microplates with high and low nutrient broth, only the filamentous yeast was able to attach and form biofilm. This was also evident when biofilm formation was assessed on peg lids. The budding yeast biofilm was hardly noticeable and recovery cell numbers after sonication were below detection level. It is likely that the filamentous yeasts may survive shear and chemical stress better due to a tighter adhesion, greater coverage and potential for making mature biofilms and they may use their hyphae to exploit temporarily induced changes of the membranes.
The recent reports on the isolation of Saprochaete and Magnusiomyces genera from household dishwashers in multigenera biofilms (Zalar et al., 2011; Döğen et al., 2013; Gümral et al., 2016; Zupančič et al., 2016) confirm their ability to colonize and persist on surfaces exposed to extreme conditions like heat, and periods of desiccation. They also suggest that these yeasts are commonly found in the general environment and it may be speculated that they are spread by a water transmission route. Although they may be common contaminants, $S$. clavata and species belonging to Magnusiomyces genera are sometimes referred to as opportunistic pathogens, since they have been associated with nosocomial outbreaks in immunocompromised patients (Gurgui et al., 2011; Birrenbach et al., 2012; Camus et al., 2014; Picard et al., 2014; Vaux et al., 2014; UluKilic et al., 2015; Del Principe et al., 2016; Favre et al., 2016; Durán Graeff et al., 2017). An association with hospital vacuum flasks was found in one outbreak, but in general, little is known about the occurrence, ecology and routes of transmission.

The data obtained from this study can serve as a new insight to understand the role that filamentous yeast may play in dual or multispecies biofilms and points toward a harboring role of the filamentous yeast species within some biofilm structures, potentially having an impact on the presence and survival of other species. In the specific setting investigated, both the retentate and the permeate were subjected to further treatment downstream before being used and in this environment the role is likely limited to occasional flux problems. However, there could be many membrane processes where these yeasts play a role and it is suggested that future investigations of biofouling should include methods targeting fungal contamination in order to clarify their relevance in different systems.

\section{CONCLUSION}

Filamentous yeast species identified as the closely related species S. clavata and M. spicifer, found to dominate biofilms on whey water associated CIP treated RO membrane retentate and permeate surfaces, were characterized by physiological/biochemical tests, stress tolerance assays and biofilm formation potential. These yeasts develop long hyphae and may cover large areas on the RO membranes compared with bacteria and budding yeasts, although they grow much slower than bacteria. Physiological and biochemical tests showed that they share similar colony and cell morphology and biochemical characteristics. The tested isolates of S. clavata and M. spicifer were found to be tolerant to heat with less than $1 \log _{10}(\mathrm{CFU} / \mathrm{mL})$ reductions of $S$. clavata at $60^{\circ} \mathrm{C}$ after $15 \mathrm{~min}$. Temperatures above $70^{\circ} \mathrm{C}$ ensured a substantial reduction of both filamentous yeasts. UV-C light at a dose level of $10 \mathrm{~mJ} / \mathrm{cm}^{2}$ had little effect, while doses of $40 \mathrm{~mJ} / \mathrm{cm}^{2}$ and upward ensured a $4 \mathrm{log}$ or higher reduction in a static laboratory scale set-up. Both filamentous isolates were able to metabolize urea and grew in the low nutrient twice RO-filtrated permeate.

Magnusiomyces spicifer and S. lactativora formed robust biofilms on RO membrane coupons that survived sanitizing 
treatments applied in lab-scale experiments, mimicking industrial CIP treatments. When a filamentous S. clavata isolate and a budding yeast S. lactativora isolate, both isolated from a RO membrane, were tested for biofilm formation on polystyrene microtiter plates, the filamentous yeast formed a copious biofilm according to $0.1 \% \mathrm{CV}$ and XTT/menadione staining, as well as on peg lids, while the budding yeast S. lactativora isolate did not. When both yeasts were combined, a robust mixed biofilm was formed on peg lids indicating that the filamentous yeast can act as a harbor for the attachment and proliferation of other microorganisms. There has previously been little focus on these filamentous yeasts and the existing sequencing databases reflect the current limitations regarding taxonomy. Their ability, demonstrated here, to attach and proliferate in stressful, nutrient poor environments helps to explain how they persist on membrane surfaces despite regular CIP treatments and is thus a step towards understanding their role in membrane biofouling and flux as well as a potential impact on the quality of retentates and permeates.

\section{DATA AVAILABILITY STATEMENT}

The datasets generated for this study are available on request to the corresponding author.

\section{REFERENCES}

Anand, S., Hassan, A., and Avadhanula, M. (2012). The effects of biofilms formed on whey reverse osmosis membranes on the microbial quality of the concentrated product. Int. J. Dairy Technol. 65, 451-455. doi: 10.1111/j.14710307.2012.00848.x

Anand, S., Singh, D., Avadhanula, M., and Marka, S. (2013). Development and control of bacterial biofilms on dairy processing membranes. Compr. Rev. Food Sci. Food Saf. 13, 18-33. doi: 10.1111/1541-4337.1 2048

Babič, M. N., Gunde-Cimerman, N., Vargha, M., Tischner, Z., Magyar, D., Veríssimo, C., et al. (2017). Fungal contaminants in drinking water regulation? A tale of ecology, exposure, purification and clinical relevance. Int. J. Environ. Res. Public Health 14:636. doi: 10.3390/ijerph1406 0636

Birrenbach, T., Bertschy, S., Aebersold, F., Mueller, N. J., Achermann, Y., Muehlethaler, K., et al. (2012). Emergence of Blastoschizomyces capitatus yeast infections, Central Europe. Emerg. Infect. Dis. 18, 98-101. doi: 10.3201/eid1801. 111192

Bolton, J., Beck, S., and Linden, K. (2015). Protocol for the Determination of Fluence (UV Dose) Using A Low-Pressure or Low-Pressure High-Output UV Lamp in Bench-Scale Collimated Beam Ultraviolet Experiments. Boulder, CO: University of Colorado at Boulder.

Bolton, J. R., and Linden, K. G. (2003). Standardization of methods for Fluence (UV Dose) determination in Bench-Scale UV experiments. J. Environ. Eng. 129, 209-215. doi: 10.1061/(ASCE)0733-93722003129:3(209)

Booth, J. L., and Vishniac, H. S. (1987). Urease testing and yeast taxonomy. Can. J. Microbiol. 33, 396-404. doi: 10.1139/m87-069

Bowker, C., Sain, A., Shatalov, M., and Ducoste, J. (2011). Microbial UV fluenceresponse assessment using a novel UV-LED collimated beam system. Water Res. 45, 2011-2019. doi: 10.1016/j.watres.2010.12.005

Buzrul, S., and Alpas, H. (2007). Modeling inactivation kinetics of food borne pathogens at a constant temperature. LWT Food Sci. Technol. 40, 632-637. doi: 10.1016/j.lwt.2006.02.019

\section{AUTHOR CONTRIBUTIONS}

EV conceptualized and designed the work, acquired, analyzed and interpreted the data, wrote and reviewed the manuscript. SA contributed to the initial acquisition of data and review of the manuscript. NM acquired the data and reviewed the manuscript. SK conceptualized the work, supervised the project, interpreted the data and reviewed the manuscript. All authors read and approved the final manuscript.

\section{FUNDING}

This work was supported by the REuse of WAteR in the Food and Bioprocessing Industries consortium (REWARD: 130800027B) funded by the Danish Council for Strategic Research, Programme Commission on Health Food and Welfare and a Ph.D. scholarship for EV co-funded by the Danish Partnership for Resource and Water Efficient Industrial Food Production (DRIP: j.nr. 152-2014-10), and University of Copenhagen.

\section{ACKNOWLEDGMENTS}

We gratefully acknowledge Peter Baek Skou for conducting the urea/ammonia analysis.

Camus, V., Thibault, M.-L., David, M., Gargala, G., Compagnon, P., Lamoureux, F., et al. (2014). Invasive Geotrichum clavatum fungal infection in an acute Myeloid Leukaemia patient: a case report and review. Mycopathologia 177, 319-324. doi: 10.1007/s11046-014-9746-9744

Casani, S., and Knøchel, S. (2002). Application of HACCP to water reuse in the food industry. Food Control 13, 315-327. doi: 10.1016/S0956-7135(02)00 037-33

Casani, S., Rouhany, M., and Knøchel, S. (2005). A discussion paper on challenges and limitations to water reuse and hygiene in the food industry. Water Res. 39, 1134-1146. doi: 10.1016/j.watres.2004. 12.015

De Brucker, K., Tan, Y., Vints, K., De Cremer, K., Braem, A., Verstraeten, N., et al. (2015). Fungal $\beta$-1,3-glucan increases ofloxacin tolerance of Escherichia coli in a polymicrobial E. coli/Candida albicans biofilm. Antimicrob. Agents Chemother. 59, 3052-3058. doi: 10.1128/AAC.046504614

Del Principe, M. I., Sarmati, L., Cefalo, M., Fontana, C., De Santis, G., Buccisano, F., et al. (2016). A cluster of Geotrichum clavatum (Saprochaete clavata) infection in haematological patients: a first Italian report and review of literature. Mycoses 59, 594-601. doi: 10.1111/myc. 12508

Döğen, A., Kaplan, E., Öksüz, Z., Serin, M. S., Ilkit, M., and Sybren de Hoog, G. (2013). Dishwashers are a major source of human opportunistic yeast-like fungi in indoor environments in Mersin. Turkey. Med. Mycol. 51, 493-498. doi: $10.3109 / 13693786.2012 .738313$

Doggett, M. S. (2000). Characterization of fungal biofilms within a municipal water distribution system. Appl. Environ. Microbiol. 66, 1249L-1251L. doi: 10.1128/ aem.66.3.1249-1251.2000

Doyle, M. E., Mazzotta, A. S., Wang, T., Wiseman, D. W., and Scott, V. N. (2001). Heat Resistance of Listeria monocytogenes. J. Food Prot. 64, 410-429. doi: 10.4315/0362-028X-64.3.410

Durán Graeff, L., Seidel, D., Vehreschild, M. J. G. T., Hamprecht, A., Kindo, A., Racil, Z., et al. (2017). Invasive infections due to Saprochaete and Geotrichum species: report of 23 cases from the FungiScope Registry. Mycoses 60, 273-279. doi: $10.1111 /$ myc. 12595 
Favre, S., Rougeron, A., Levoir, L., Pérard, B., Milpied, N., Accoceberry, I., et al. (2016). Saprochaete clavata invasive infection in a patient with severe aplastic anemia: efficacy of voriconazole and liposomal amphotericin B with adjuvant granulocyte transfusions before neutrophil recovery following allogeneic bone marrow transplantation. Med. Mycol. Case Rep. 11, 21-23. doi: 10.1016/j.mmcr. 2016.03.001

Gümral, R., Özhak-Baysan, B., Tümgör, A., Saraçlı, M. A., Yıldıran, S. T., Ilkit, M., et al. (2016). Dishwashers provide a selective extreme environment for humanopportunistic yeast-like fungi. Fungal Divers. 76, 1-9. doi: 10.1007/s13225-0150327-328

Gurgui, M., Sanchez, F., March, F., Lopez-Contreras, J., Martino, R., Cotura, A., et al. (2011). Nosocomial outbreak of Blastoschizomyces capitatus associated with contaminated milk in a haematological unit. J. Hosp. Infect. 78, 274-278. doi: 10.1016/j.jhin.2011.01.027

Harrison, J. J., Stremick, C. A., Turner, R. J., Allan, N. D., Olson, M. E., and Ceri, H. (2010). Microtiter susceptibility testing of microbes growing on peg lids: a miniaturized biofilm model for high-throughput screening. Nat. Protoc. 5:1236. doi: $10.1038 /$ nprot.2010.71

Hassan, A. N., Anand, S., and Avadhanula, M. (2010). Microscopic observation of multispecies biofilm of various structures on whey concentration membranes. J. Dairy Sci. 93, 2321-2329. doi: 10.3168/jds.2009-2800

Herzberg, M., and Elimelech, M. (2007). Biofouling of reverse osmosis membranes: role of biofilm-enhanced osmotic pressure. J. Memb. Sci. 295, 11-20. doi: 10. 1016/j.memsci.2007.02.024

Kirchhoff, L., Olsowski, M., Zilmans, K., Dittmer, S., Haase, G., Sedlacek, L., et al. (2017). Biofilm formation of the black yeast-like fungus Exophiala dermatitidis and its susceptibility to antiinfective agents. Sci. Rep. 7:42886. doi: 10.1038/ srep42886

Kurtzman, C. P., Fell, J. W., Boekhout, T., and Robert, V. (2011). "Chapter 7 methods for isolation, phenotypic characterization and maintenance of yeasts," in The Yeasts, 5TH Edn, eds C. P. Kurtzman, and J. W. Fell (London: Elsevier), 87-110. doi: 10.1016/B978-0-444-52149-1.00007-0

Lachance, M.-A. (2011). "Chapter 69 - Sporopachydermia Rodrigues de Miranda (1978)," in The Yeasts, eds. C. P. Kurtzman, J. W. Fell, and T. B. T.-T. Y. F. E. Boekhout (London: Elsevier), 799-803. doi: 10.1016/B978-0-444-52149-1. 00069-0

Li, X., Cai, M., Wang, L., Niu, F., Yang, D., and Zhang, G. (2019). Evaluation survey of microbial disinfection methods in UV-LED water treatment systems. Sci. Total Environ. 659, 1415-1427. doi: 10.1016/j.scitotenv.2018.12.344

McCormick, K., Han, I. Y., Acton, J. C., Sheldon, B. W., and Dawson, P. L. (2003). D and z-values for Listeria monocytogenes and Salmonella typhimurium in packaged low-fat ready-to-eat turkey bologna subjected to a surface pasteurization treatment. Poult. Sci. 82, 1337-1342. doi: 10.1093/ps/82.8.1337

Murphy, R. Y., Duncan, L. K., Berrang, M. E., Marcy, J. A., and Wolfe, R. E. (2002). Thermal inactivation D- and Z-values of Salmonella and Listeria innocua in fully cooked and vacuum packaged chicken breast meat during postcook heat treatment. Poult. Sci. 81, 1578-1583. doi: 10.1093/ps/81.10.1578

Murphy, R. Y., Marks, B. P., Johnson, E. R., and Johnson, M. G. (2000). Thermal Inactivation Kinetics of Salmonella and Listeria in Ground Chicken Breast Meat and Liquid Medium. J. Food Sci. 65, 706-710. doi: 10.1111/j.1365-2621.2000. tb16076.x

Navarathna, D. H., Harris, S. D., Roberts, D. D., and Nickerson, K. W. (2010). Evolutionary aspects of urea utilization by fungi. FEMS Yeast Res. 10, 209-213. doi: $10.1111 /$ j.1567-1364.2010.00602.x

Paramonova, E., Krom, B. P., van der Mei, H. C., Busscher, H. J., and Sharma, P. K. (2009). Hyphal content determines the compression strength of Candida albicans biofilms. Microbiology 155, 1997-2003. doi: 10.1099/mic.0.02156821560

Picard, M., Cassaing, S., Letocart, P., Verdeil, X., Protin, C., Chauvin, P., et al. (2014). Concomitant cases of disseminated Geotrichum clavatum infections in patients with acute myeloid leukemia. Leuk. Lymphoma 55, 1186-1188. doi: $10.3109 / 10428194.2013 .820290$

Pierce, C. G., Uppuluri, P., Tristan, A. R., Wormley, F. L., Mowat, E., Ramage, G., et al. (2008). A simple and reproducible 96-well plate-based method for the formation of fungal biofilms and its application to antifungal susceptibility testing. Nat. Protoc. 3, 1494-1500. doi: 10.1038/nport.20 08.141
Sánchez, O. (2018). Microbial diversity in biofilms from reverse osmosis membranes: a short review. J. Memb. Sci. 545, 240-249. doi: 10.1016/j.memsci. 2017.09.082

Shirtliff, M. E., Peters, B. M., and Jabra-Rizk, M. A. (2009). Cross-kingdom interactions: Candida albicans and bacteria. FEMS Microbiol. Lett. 299, 1-8. doi: 10.1111/j.1574-6968.2009.01668.x

Simon, A., Price, W. E., and Nghiem, L. D. (2013). Influence of formulated chemical cleaning reagents on the surface properties and separation efficiency of nanofiltrationmembranes. J. Memb. Sci. 432, 73-82. doi: 10.1016/j.memsci. 2012.12.029

Skou, P. B., Berg, T. A., Aunsbjerg, S. D., Thaysen, D., Rasmussen, M. A., and van den Berg, F. (2017). Monitoring process water quality using near infrared spectroscopy and partial least squares regression with prediction uncertainty estimation. Appl. Spectrosc. 71, 410-421. doi: 10.1177/000370281665 4165

Skou, P. B., Khakimov, B., Hansen, T. H., Aunsbjerg, S. D., Knøchel, S., Thaysen, D., et al. (2018). Chemical characterization by gas chromatography-mass spectrometry and inductively coupled plasma-optical emission spectroscopy of membrane permeates from an industrial dairy ingredient production used as process water. J. Dairy Sci. 101, 135-146. doi: 10.3168/jds.201712950

Song, K., Mohseni, M., and Taghipour, F. (2016). Application of ultraviolet lightemitting diodes (UV-LEDs) for water disinfection: a review. Water Res. 94, 341-349. doi: 10.1016/j.watres.2016.03.003

Souciet, J.-L., Aigle, M., Artiguenave, F., Blandin, G., Bolotin-Fukuhara, M., Bon, E., et al. (2000). Genomic exploration of the Hemiascomycetous Yeasts: 1. A set of yeast species for molecular evolution studies. FEBS Lett. 487, 3-12. doi: 10.1016/S0014-5793(00)02272-2279

Stoica, I. M., Vitzilaiou, E., Lyng Røder, H., Burmølle, M., Thaysen, D., Knøchel, S., et al. (2018). Biofouling on RO-membranes used for water recovery in the dairy industry. J. Water Process Eng. 24, 1-10. doi: 10.1016/j.jwpe.2018. 05.004

Strope, P. K., Nickerson, K. W., Harris, S. D., and Moriyama, E. N. (2011). Molecular evolution of urea amidolyase and urea carboxylase in fungi. BMC Evol. Biol. 11:80. doi: 10.1186/1471-2148-11-80

Sybren De Hoog, G., and Smith, M. (2004). Ribosomal gene phylogeny and species delimitation in Geotrichum and its teleomorph. Stud. Mycol. 50, 489-515. doi: 10.1016/j.funbio.2010.01.007

Sybren De Hoog, G., and Smith, M. (2011a). "Chapter 45 - Magnusiomyces Zender (1977)," in The Yeasts, 5th Edn, eds C. P. Kurtzman, and J. W. Fell (London: Elsevier), 565-574. doi: 10.1016/B978-0-444-52149-1.0 0045-8

Sybren De Hoog, G., and Smith, M. (2011b). "Chapter 97 - Saprochaete Coker \& Shanor ex D.T.S. Wagner \& Dawes (1970)," in The Yeasts, 5th Edn, eds C. P. Kurtzman, and J. W. Fell (London: Elsevier), 1317-1327. doi: 10.1016/B978-0444-52149-1.00097-5

Tang, X., Flint, S. H., Brooks, J. D., and Bennett, R. J. (2009). Factors affecting the attachment of micro-organisms isolated from ultrafiltration and reverse osmosis membranes in dairy processing plants. J. Appl. Microbiol. 107, 443-451. doi: 10.1111/j.1365-2672.2009.04214.x

Tarifa, M. C., Brugnoni, L. I., and Lozano, J. E. (2013). Role of hydrophobicity in adhesion of wild yeast isolated from the ultrafiltration membranes of an apple juice processing plant. Biofouling 29, 841-853. doi: 10.1080/08927014. 2013.808628

Ulu-Kilic, A., Atalay, M. A., Metan, G., Cevahir, F., Koç, N., Eser, B., et al. (2015). Saprochaete capitata as an emerging fungus among patients with haematological malignencies. Mycoses 58, 491-497. doi: 10.1111/myc. 12347

Vaux, S., Criscuolo, A., Desnos-Ollivier, M., Diancourt, L., Tarnaud, C., Vandenbogaert, M., et al. (2014). Multicenter outbreak of infections by Saprochaete clavata, an unrecognized opportunistic fungal pathogen. mBio 5, 1-10. doi: 10.1128/mBio.02309-2314

Vitzilaiou, E., Stoica, I. M., and Knøchel, S. (2019). Microbial biofilm communities on Reverse Osmosis membranes in whey water processing before and after cleaning. J. Memb. Sci. 587:117174. doi: 10.1016/j.memsci.2019.117174

Zalar, P., Novak, M., Sybren de Hoog, G., and Gunde-Cimerman, N. (2011). Dishwashers - A man-made ecological niche accommodating human 
opportunistic fungal pathogens. Fungal Biol. 115, 997-1007. doi: 10.1016/j. funbio.2011.04.007

Zupančičc, J., Novak Babič, M., Zalar, P., and Gunde-Cimerman, N. (2016). The Black Yeast Exophiala dermatitidis and other selected opportunistic human fungal pathogens spread from dishwashers to kitchens. PLoS One 11:e0148166. doi: 10.1371/journal.pone. 0148166

Zupančič, J., Raghupathi, P. K., Houf, K., Burmølle, M., Sørensen, S. J., and Gunde-Cimerman, N. (2018). Synergistic interactions in microbial biofilms facilitate the establishment of opportunistic pathogenic fungi in household dishwashers. Front. Microbiol. 9:21. doi: 10.3389/fmicb.2018. 00021
Conflict of Interest: The authors declare that the research was conducted in the absence of any commercial or financial relationships that could be construed as a potential conflict of interest.

Copyright () 2020 Vitzilaiou, Aunsbjerg, Mahyudin and Knøchel. This is an openaccess article distributed under the terms of the Creative Commons Attribution License (CC BY). The use, distribution or reproduction in other forums is permitted, provided the original author(s) and the copyright owner(s) are credited and that the original publication in this journal is cited, in accordance with accepted academic practice. No use, distribution or reproduction is permitted which does not comply with these terms. 